\title{
Aerosol measurements at the Gual Pahari EUCAARI station: preliminary results from in-situ measurements
}

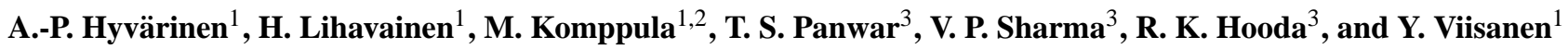 \\ ${ }^{1}$ Finnish Meteorological Institute, Erik Palménin aukio 1, P.O. Box 503, 00101, Helsinki, Finland \\ ${ }^{2}$ Finnish Meteorological Institute, Yliopistonranta 1F, P.O. Box 1627, 70211 Kuopio, Finland \\ ${ }^{3}$ The Energy and Resources Institute (TERI), Darbari Seth Block, IHC Complex, Lodhi Road, New Delhi 110 003, India
}

Received: 25 March 2010 - Published in Atmos. Chem. Phys. Discuss.: 8 April 2010

Revised: 22 June 2010 - Accepted: 18 July 2010 - Published: 6 August 2010

\begin{abstract}
The Finnish Meteorological Institute (FMI), together with The Energy and Resources Institute of India (TERI), contributed to the European Integrated project on Aerosol Cloud Climate and Air Quality Interactions, EUCAARI, by conducting aerosol measurements in Gual Pahari, India, from December 2007 to January 2010. This paper describes the station setup in detail for the first time and provides results from the aerosol in-situ measurements, which include $\mathrm{PM}$ and $\mathrm{BCe}$ masses, aerosol size distribution from $4 \mathrm{~nm}$ to $10 \mu \mathrm{m}$, and the scattering and absorption coefficients. The seasonal variation of the aerosol characteristics was very distinct in Gual Pahari. The highest concentrations were observed during the winter and the lowest during the rainy season. The average $\mathrm{PM}_{10}$ concentration (at STP conditions) was $216{\mu g m^{-3}}^{-3}$ and the average $\mathrm{PM}_{2.5}$ concentration was $126 \mu \mathrm{gm}^{-3}$. A high percentage (4-9\%) of the $\mathrm{PM}_{10}$ mass consisted of $\mathrm{BCe}$ which indicates anthropogenic influence. The percentage of $\mathrm{BCe}$ was higher during the winter; and according to the diurnal pattern of the $\mathrm{BCe}$ fraction, the peak occurred during active traffic hours. Another important source of aerosol particles in the area was new particle formation. The nucleated particles grew rapidly reaching the Aitken and accumulation mode size, thus contributing considerably to the aerosol load. The rainy season decreased the average fraction of particle mass in the $\mathrm{PM}_{2.5}$ size range, i.e. of secondary origin. The other mechanism decreasing the surface concentrations was based on convective mixing and
\end{abstract}

Correspondence to: A.-P. Hyvärinen (antti.hyvarinen@fmi.fi) boundary layer evolution. This diluted the aerosol when sun radiation and the temperature was high, i.e. especially during the pre-monsoon day time. The lighter and smaller particles were more effectively diluted.

\section{Introduction}

Southern Asia, including India, is exposed to substantial quantities of particulate air pollution. This layer of particulate pollution that can be observed also from satellites is often referred to as atmospheric brown cloud (Lelieveld et al., 2001; Nakajima et al., 2007; Ramanathan et al., 2007a, b). Brown cloud generally denotes anthropogenic aerosols that not only scatter but absorb solar radiation due to black carbon and other absorbing materials. The brown cloud is assumed to be originating from fossil fuel and biomass burning besides natural sources such as desert dust (e.g. Hegde et al., 2007; Ramanathan et al., 2007a). By modifying the spatial and temporal distribution of temperature of the lower troposphere, rainfall and radiation fluxes, absorbing aerosol particles are likely to have significant influences on photolysis rates, ozone chemistry, crop yields, livestock and water resources over the southern Asia (e.g. Satheesh and Ramanathan, 2000; Singh et al., 2004; Pathirana et al., 2007; Sirohi and Michaclowa, 2007). One of the most striking examples of the climatic effect by absorbing aerosols over India is their possible ability to modify the annual monsoon (Lau and Kim, 2006; Bollasina et al., 2008; Meehl et al., 2008).

Published by Copernicus Publications on behalf of the European Geosciences Union. 
Several field experiments linked with atmospheric aerosols (e.g. INDOEX, ACE-Asia, TRACE-P, APEX and PEACE) have been conducted in the Asian region, partly because this region is expected to grow rapidly resulting in enhanced air pollution, and also because Asian aerosols may have significant direct and indirect effects on the regional and even global climate system (Nakajima el al., 2007). There has been a lack of long-term measurement of aerosol properties in the southern Asia, especially from background areas. Only recently there have been attempts to establish longterm, high quality, aerosol measurement stations in India and other countries in the area (e.g. Carrico et al., 2003; Gajananda et al., 2005; Ramanathan et al., 2007a; Bonasoni et al., 2008, Hyvärinen et al., 2009, Komppula et al., 2009).

The Finnish Meteorological Institute (FMI), together with The Energy and Resources Institute of India (TERI), have contributed to the European Integrated project on Aerosol Cloud Climate and Air Quality Interactions, EUCAARI, by conducting aerosol measurements in Gual Pahari, India, from December 2007 to January 2010. This paper describes the station setup in detail for the first time and provides results from the aerosol in-situ measurements, which include PM and $\mathrm{BC}$ masses, aerosol size distribution from $4 \mathrm{~nm}$ to $10 \mu \mathrm{m}$, and the scattering and absorption coefficients.

\section{Experimental methods}

\subsection{Station overview and instrumentation}

The measurement site (Fig. 1) was located in Gual Pahari (28.43 ${ }^{\circ}$ North, $77.15^{\circ}$ East, $243 \mathrm{~m}$ a.s.1.), Gurgaon, about $25 \mathrm{~km}$ south of New Delhi. The surroundings represent a semi-urban environment, with Delhi located about $25 \mathrm{~km}$ north of the station (population $\sim 13850500$, Census of India 2001). The station was built in a standard 20 feet sea container with air conditioning, thermal insulation between outer and inner walls, an internal electricity board and UPS's for power stabilization. In addition, the container was shaded with a light tent to prevent excessive heating by direct sunlight.

The air was sampled through three inlets mounted $1.5-2 \mathrm{~m}$ above the roof, all with a flow rate of $16.71 / \mathrm{min}$. Two separate inlets with $\mathrm{PM}_{2.5}$ and $\mathrm{PM}_{10}$ cut-off were used for sampling with the two individual Particulate Mass (PM) monitors (Thermo Scientific, beta hybrid mass monitors). The PMinlets used standard heaters for drying the sample air. The main inlet with a $\mathrm{PM}_{10}$ cut-off had the following instrumentation:

- Twin-Differential Mobility Particle Sizer (DMPS, particle number size distribution over the diameter range 4-850 nm, total particle number concentration).

- Number concentration measured with TSI 3772 CPC's (condensation particle counter).
- Short Hauke-type DMA sizing the low diameter range of $4-58 \mathrm{~nm}$.

- Medium Hauke-type DMA sizing the high diameter range of $31-850 \mathrm{~nm}$.

- Aerosol Particle Sizer, TSI 3321 (APS, particle number size distribution over the diameter range $0.5-10 \mu \mathrm{m})$.

- Multi-angle Absorption Photometer, Thermo Scientific (MAAP, aerosol black carbon concentration, absorption coefficient at $670 \mathrm{~nm}$ ).

- Nephelometer, Ecotech (aerosol scattering coefficient at $520 \mathrm{~nm}$ ).

To assure that data was valid, the instruments were calibrated regularly. The flow rates of each instrument and zero checks with HEPA filters were made once a month. The flow rates were allowed to drift by $\pm 5 \%$. Automatic zero calibrations (with HEPA filter) for the nephelometer were made every three hours and full calibrations with $\mathrm{CO}_{2}$-gas every month. The PM monitors were calibrated against reference mass filters every three months.

The main inlet used a diffusion drier that removed humidity from the sample stream. Until 13 March 2008 a Nafion dryer (Model DD-600) was used, which was then replaced by a twin-diffusion drier. In the twin drier, seven $1 \mathrm{~cm}$ diameter netted tubes traveled for a distance of $1 \mathrm{~m}$ inside the drying media in two units. The drying media was molecular sieve granules. One unit was active (sampling) at a given time, while the molecular sieve of inactive unit was dried with $401 / \mathrm{min}$ of compressed, dry air. The sampling/drying was switched between the units with a $45 \mathrm{~min}$ interval. This kept the relative humidity mainly below $40 \%$. However during the rainy season, the outside dew point was so high that even with the dryer, RH could not be maintained always below $50 \%$.

In addition to the aerosol measurements conducted in the container, ambient temperature, relative humidity, rain intensity, wind direction and wind speed were measured with a Vaisala WXT weather station. The sensor was mounted $3 \mathrm{~m}$ above the container roof. Also other measurements were conducted within the period of the project. These instruments included the Cimel sunphotometer for columnar Aerosol optical depth (AOD), the PollyXT LIDAR (Althausen et al., 2009), and the Partisol Filter sampler for measurements of aerosol mass, EC/OC fraction and inorganic chemistry. Out of these the Cimel was operational from November 2008 to the end of the campaign, the LIDAR from March 2008 to March 2009, and the Partisol from March 2008 to January 2009.

The station was located in an area where only electricpowered vehicles are allowed. The station was surrounded mainly by agricultural test fields and light vegetation. There were no major local pollution sources, except for the road between Gurgaon and Faridabad about $0.5 \mathrm{~km}$ to the south-west 


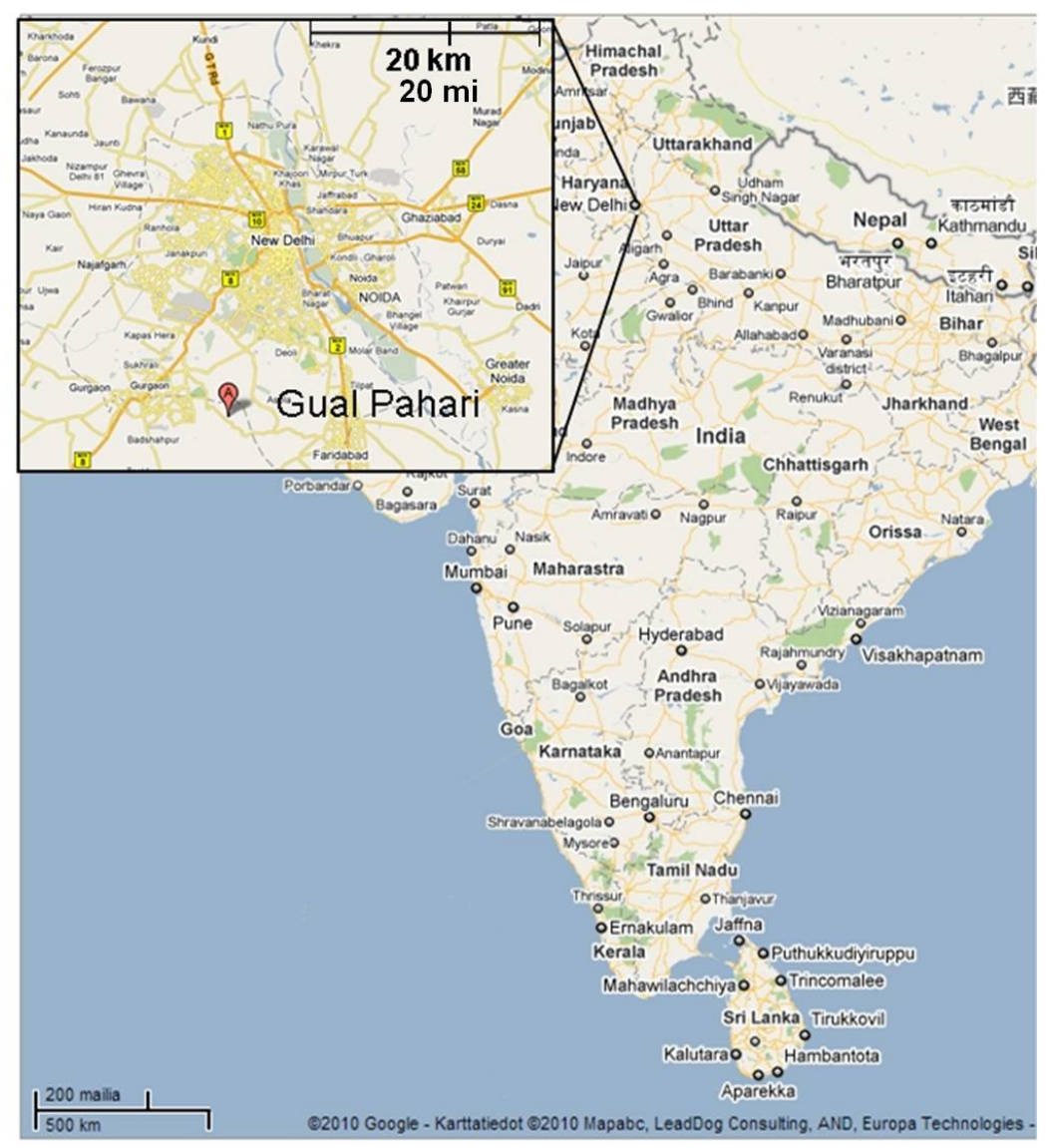

Fig. 1. Location of the Gual Pahari measurement station.

of the station. In addition, some houses within a distance of about $1 \mathrm{~km}$ used biomass for cooking purposes. The measurements in the container were begun in December 2007 and ended in January 2010

\subsection{Data evaluation}

The measured data was saved as five minute averages. The five minute data was checked with outliers and obvious instrument malfunctions periods removed. The data was then averaged to one hour with the condition that each hour had more than $25 \mathrm{~min}$ of data. All longer time averages were calculated from the hourly data, which was also converted to STP-conditions. One month averages were only calculated if the data covered more than $30 \%$ of the time. For seasonal analyses, the year was divided into four seasons: winter (December-February), pre-monsoon (Mar-onset of monsoon), rainy season (onset of monsoon-withdrawal of monsoon) and post-monsoon (withdrawal of monsoon-Nov). The onset and withdrawal dates of monsoon were taken as those determined by the Indian Meteorological Department (IMD).

Backward trajectories were calculated for every three hours with the FLEXTRA model (Stohl et al., 1995) for the
950-hPa pressure level. For further trajectory analysis, the surroundings were split into $30^{\circ}$ sectors to enable a more detailed investigation of the source areas of particulate pollution. For each trajectory, a number of quantities were calculated, including the sectors in which the air was 24,72 and $120 \mathrm{~h}$ prior to its arrival at the measurement sites, the fraction of time the air had spent in each sector, average heights above sea level and above ground level. Taken together, this provides a good basis for distinguishing between different air masses to quantify their influence on measured aerosol properties.

\section{Results}

\subsection{Meteorological parameters}

The ambient meteorological parameters were measured with a Vaisala WXT weather station. The $1 \mathrm{~h}$ data coverage for the measured weather parameter was $91 \%$. As typical for the Indian sub-continent, the weather exhibited a clear seasonal pattern. The meteorological parameters are presented in Fig. 2 and Table 1. 
Table 1. Mean, minimum and maximum (1 h average) temperature, $T$, relative humidity, RH, pressure, $P$, and wind speed, WS during different seasons.

\begin{tabular}{|c|c|c|c|c|c|c|c|}
\hline & \multicolumn{2}{|c|}{$T,{ }^{\circ} \mathrm{C}$} & \multicolumn{2}{|c|}{$\mathrm{RH}, \%$} & \multicolumn{2}{|c|}{$P, \mathrm{hPa}$} & $\mathrm{WS}, \mathrm{m} / \mathrm{s}$ \\
\hline Pre-monsoon mean & \multicolumn{2}{|c|}{27.5} & \multicolumn{2}{|c|}{43.0} & \multicolumn{2}{|c|}{976.3} & 0.9 \\
\hline Max/min & 43.2 & 8.3 & 95.1 & 5.7 & 990.2 & 963.9 & $5.9 \quad 0.1$ \\
\hline Rainy season mean & \multicolumn{2}{|c|}{27.9} & \multicolumn{2}{|c|}{74.6} & \multicolumn{2}{|c|}{972.4} & 0.8 \\
\hline $\max / \min$ & 40.0 & 18.1 & 93.3 & 20.2 & 980.9 & 964.2 & $2.8 \quad 0.1$ \\
\hline Post-monsoon mean & \multicolumn{2}{|c|}{20.6} & \multicolumn{2}{|c|}{65.5} & \multicolumn{2}{|c|}{982.7} & 0.5 \\
\hline $\max / \min$ & 35.2 & 4.0 & 93.0 & 13.7 & 991.2 & 973.4 & $2.9 \quad 0.1$ \\
\hline Winter mean & \multicolumn{2}{|c|}{13.2} & \multicolumn{2}{|c|}{66.5} & \multicolumn{2}{|c|}{986.4} & 0.7 \\
\hline $\max / \min$ & 30.3 & 0.1 & 96.6 & 14.8 & 995.3 & 977.7 & 5.8 \\
\hline
\end{tabular}
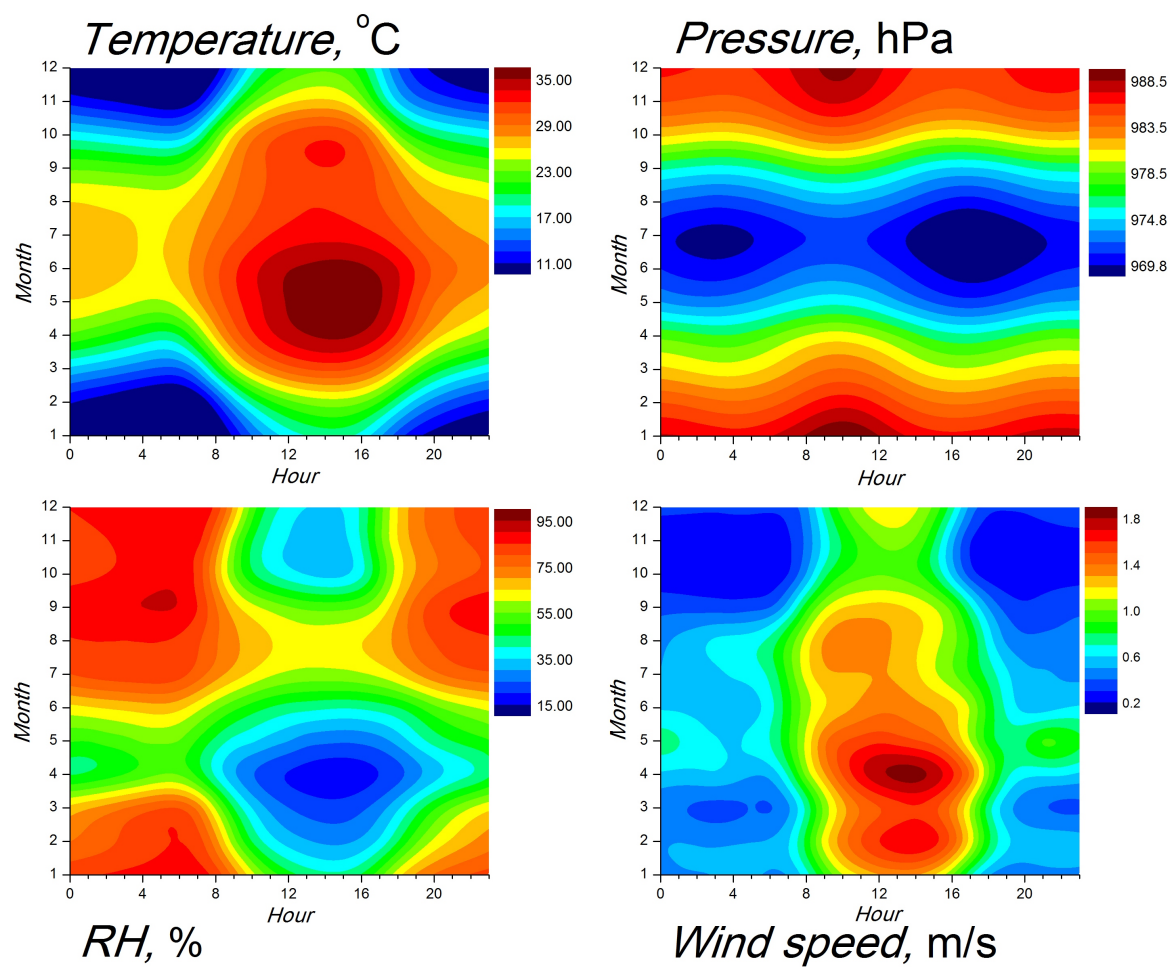

Fig. 2. Meteorological parameters measured at Gual Pahari during the campaign.

The average temperatures were highest during the rainy season, but the maximum temperature was found during the pre-monsoon season. This is due to much higher diurnal temperature gradient during the pre-monsoon. During the winter, the coldest nights reached zero degrees ${ }^{\circ} \mathrm{C}$. The highest average relative humidity took place during the rainy season, while the maximum RH's were observed during the winter, due to the very cold nights. The highest difference between the maximum and minimum RH took place during the premonsoon season due to high diurnal variation of the temperature.
The annual variation of pressure was characterized by low values during the rainy season and high values during winter. The prevailing day time wind direction was most commonly from $270-300^{\circ}$ (West to West-west north). During June and July the main wind direction shifted to $60-90^{\circ}$ (East-east North to East). Day time exhibited the highest wind speeds. The wind speeds generally followed the temperature, which was related to natural convection and evolution of the boundary layer. 


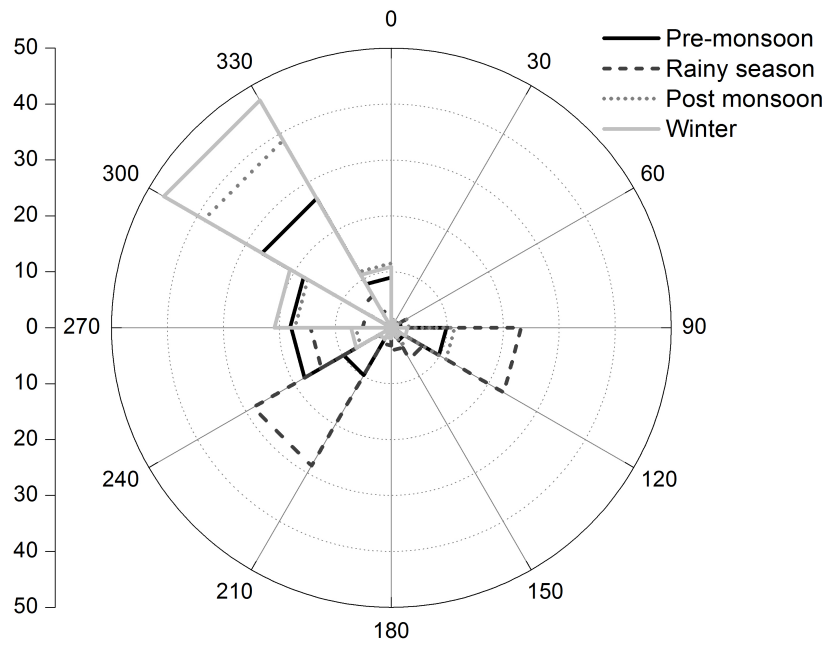

Fig. 3. Trajectory occurrence- $\%$ as a function of the main $30^{\circ}$ sector during different seasons.

Figure 3 illustrates the trajectory sector occurrences during different seasons as a fraction of time the trajectories had spent in each sector. During winter the prevailing trajectory direction was $300-330^{\circ}$ with about $47 \%$ contribution. A similar pattern was seen during the post-monsoon season, which also contained a small contribution $(11 \%)$ from the $90-120^{\circ}$ sector, i.e. from the Indian Ocean. The trajectory occurrence was less clear during the pre-monsoon season, showing a $27 \%$ contribution from the $300-330$ and $18 \%$ from the 240 $270^{\circ}$ sector, i.e. from the Arabian Sea. This illustrates how the general circulation pattern evolved with the on-coming rainy season. During the rainy season, a $43 \%$ contribution was obtained from the $210-270^{\circ}$ sectors, and $23 \%$ from the $90-120^{\circ}$ sector. Quite interestingly, the $0-60^{\circ}$ sector as well as the $120-210^{\circ}$ sectors denoted very little to the incoming air masses.

\subsection{Aerosol in situ properties}

\subsubsection{Mass and BC concentrations}

The PM masses were measured individually from two inlets. The $1 \mathrm{~h}$ data coverage for the $\mathrm{PM}_{10}$ and $\mathrm{PM}_{2.5}$ was 83 and $71 \%$, respectively. The average $\mathrm{PM}_{10}$ concentration for the whole campaign was $216 \mu \mathrm{gm}^{-3}$, and the average $\mathrm{PM}_{2.5}$ concentration was $126 \mu \mathrm{gm}^{-3}$ (Table 2). Both $\mathrm{PM}_{2.5}$ and $\mathrm{PM}_{10}$ followed the same general behavior, with some individual differences. The annual variation was characterized by maximum concentrations during the winter and minimum during the rainy season, see Fig. 4 and Table 2. Both $\mathrm{PM}_{10}$ and $\mathrm{PM}_{2.5}$ concentrations were slightly higher during the postmonsoon period than during the pre-monsoon period. The average mass of particles from 2.5 to $10 \mu \mathrm{m}$ (from here on denoted as the coarse mode) had a maximum of $103 \mu \mathrm{gm}^{-3}$ during winter, and a minimum of $45 \mathrm{gmm}^{-3}$ during the rainy

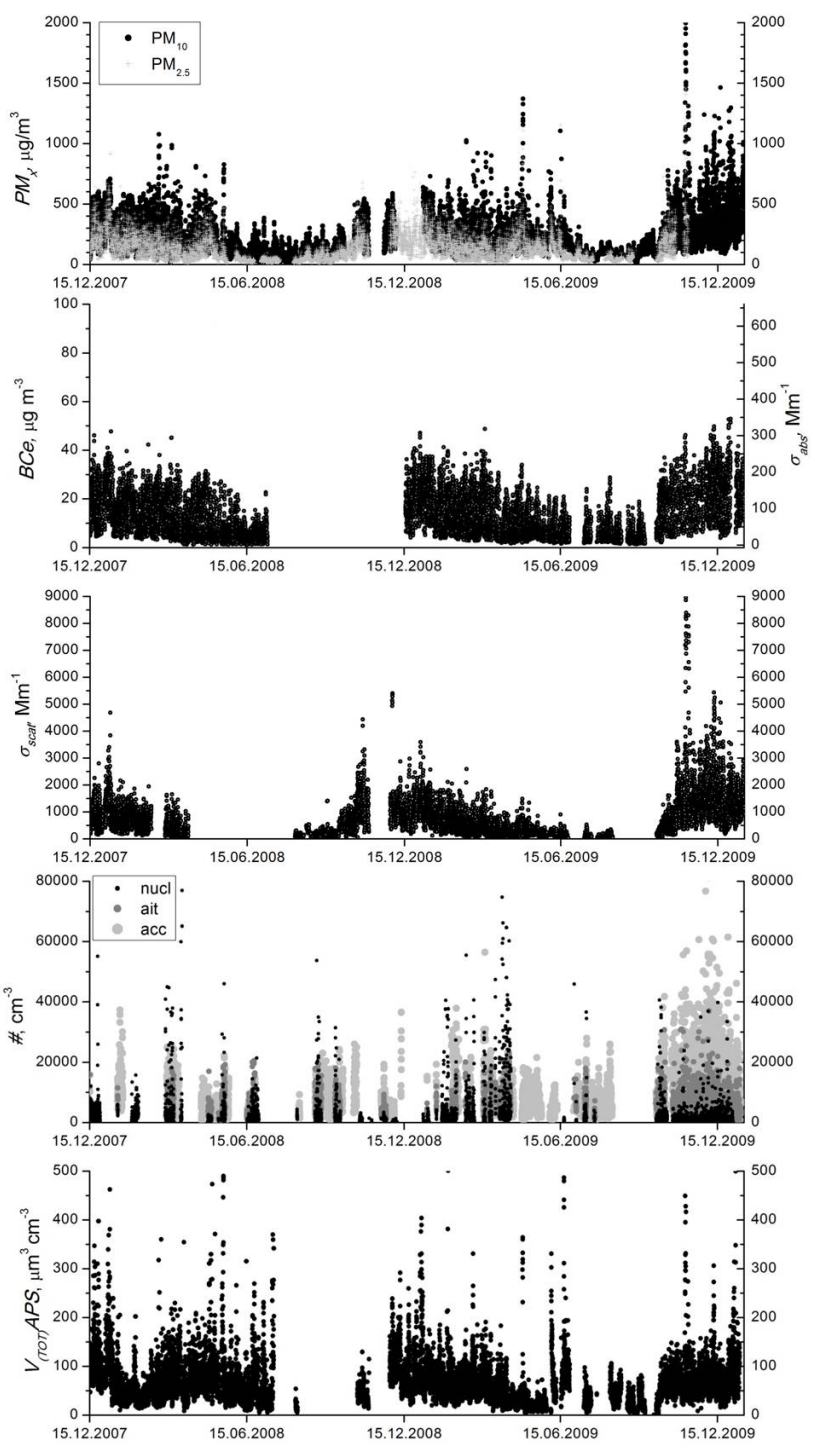

Fig. 4. Aerosol properties at Gual Pahari during the campaign. Each point corresponds to a $1 \mathrm{~h}$ average.

season. Coarse mode averages during pre- and post-monsoon were $89 \mu \mathrm{gm}^{-3}$ and $85 \mu \mathrm{gm}^{-3}$, respectively.

The aerosol Black Carbon concentration (BC) was measured from the main inlet. The $1 \mathrm{~h}$ data coverage for the measured BC was $64 \%$. Here we would like to point out that the absorption measurements conducted by the MAAP should be denoted as "equivalent black carbon, BCe" rather than the conventional "black carbon" as filter based measurements cannot be un-ambiguously converted to BC (e.g. Andreae and Gelencsér, 2006).

The average BCe concentration was $12.3 \mu \mathrm{gm}^{-3}$ (Table 2), but it has to be pointed out that the data for most of the rainy season 2008 and the post-monsoon 2008 period are missing, due to condensational damage to the instrument during the rainy season that year. The maximum $1 \mathrm{~h}$ average 
Table 2. Mean and standard deviation for PM masses, equivalent black carbon (BCe), absorption coefficient $\left(\sigma_{\mathrm{abs}}\right)$, scattering coefficient $\left(\sigma_{\text {scat }}\right)$, total number concentration, and total volume concentration during different seasons.

\begin{tabular}{lcccccc}
\hline & $\begin{array}{c}\mathrm{PM}_{10} \\
\mu \mathrm{gm}^{-3}\end{array}$ & $\begin{array}{c}\mathrm{PM}_{2.5} \\
\mu \mathrm{gm}^{-3}\end{array}$ & $\begin{array}{c}\mathrm{BCe} / \sigma_{\mathrm{abs}} \\
\mu \mathrm{gm}^{-3} / \mathrm{Mm}^{-1}\end{array}$ & $\begin{array}{c}\sigma_{\text {scat }} \\
\mathrm{Mm}^{-1}\end{array}$ & $\begin{array}{c}\text { Tot. number } \\
\mathrm{cm}^{-3}\end{array}$ & $\begin{array}{c}\text { Tot. volume } \\
\mu \mathrm{m}^{3} \mathrm{~cm}^{-3}\end{array}$ \\
\hline Pre-monsoon mean & 199 & 112 & $9.4 / 62$ & 324 & 22050 & 64 \\
St. dev. & 135 & 86 & $7.7 / 51$ & 259 & 13070 & 53 \\
Rainy season mean & 93 & 45 & $4.4 / 29$ & 151 & 16080 & 42 \\
St. dev. & 52 & 26 & $3.8 / 25$ & 105 & 9730 & 41 \\
Post-monsoon mean & 274 & 169 & $16.5 / 109$ & 1085 & 23900 & 62 \\
St. dev. & 206 & 149 & $9.1 / 60$ & 1101 & 11930 & 42 \\
Winter mean & 322 & 190 & $17.7 / 117$ & 1035 & 24324 & 78 \\
St. dev. & 179 & 109 & $9.0 / 59$ & 689 & 12450 & 51 \\
Campaign mean & 216 & 126 & $12.3 / 81$ & 758 & 22600 & 66 \\
St. dev. & 170 & 109 & $9.3 / 61$ & 771 & 12400 & 51 \\
\hline
\end{tabular}

concentration during winter was $52 \mu \mathrm{gm}^{-3}$. While very high for even a semi-urban concentration, this is lower than values reported from Delhi, where concentrations up to $65 \mu \mathrm{gm}^{-3}$ have been reported (Ganguly et al., 2006). The lowest black carbon concentrations occurred during the rainy season, with an average of $4.4 \mu \mathrm{gm}^{-3}$. The percentage of $\mathrm{BCe}$ of $\mathrm{PM}_{10}$ varied between 1.5 to $8 \%$ with a minimum during day-time pre-monsoon period.

\subsubsection{Size- and volume distribution}

The aerosol size distribution was measured from $4 \mathrm{~nm}$ to $850 \mathrm{~nm}$ using a twin DMPS with the CPC's TSI model 3772. The DMPS units suffered from an irregularly re-occurring problem of voltage control freezing via the CPC's for an unknown reason. In April 2009, this problem was reduced by automatically resetting the CPC's every $12 \mathrm{~h}$. However, the problems persisted until the end of the campaign especially with the short DMA measuring the lower size range. The $1 \mathrm{~h}$ data coverage for the low size range $(4-58 \mathrm{~nm})$ and high size range $(31-850 \mathrm{~nm})$ was $24 \%$ and $33 \%$, respectively. Particle size distribution with aerodynamic diameter from 0.5 to $10 \mu \mathrm{m}$ was measured with the APS. This data was converted to volume distribution. Like the MAAP, also the APS suffered from condensation during the 2008 rainy season. The $1 \mathrm{~h}$ data coverage for the APS was $68 \%$. The particle number size distribution was mostly dominated by a mode with a maximum at around $100 \mathrm{~nm}$. We divided the size distributions into three parts based on "modes" typically identified in the Gual Pahari aerosol: the nucleation mode (particle diameter $<25 \mathrm{~nm})$, Aitken mode $(25-75 \mathrm{~nm})$ and accumulation mode $(>75 \mathrm{~nm})$. The $1 \mathrm{~h}$-average concentration from our

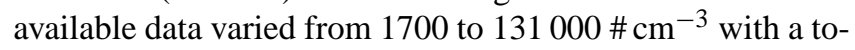
tal average of about $22600 \mathrm{\#} \mathrm{cm}^{-3}$ (Table 2). The highest observed total particle concentrations occurred due to new particle formation events. A typical event and subsequent growth extending to the next day is shown in Fig. 5. New particle formation occurred very often (in about $70 \%$ of days when information about the nucleation mode was available) in Gual Pahari. This also affected the size distribution as a whole: the nucleation and Aitken modes dominate the size distribution from March to September (Fig. 6). From October to March the accumulation mode dominated.

The volume distribution measured with the APS shows that the aerosol volume was dominated by a modes peaking at 3.5 and $0.75 \mu \mathrm{m}$. During pre-monsoon and rainy season, the $3.5 \mu \mathrm{m}$ mode dominated, while during post-monsoon and especially during winter, the $0.75 \mu \mathrm{m}$ mode dominated. The average total volume of the aerosol was $66 \mu \mathrm{m}^{3} \mathrm{~cm}^{-3}$.

\subsubsection{Optical properties}

The optical in situ properties were measured with the nephelometer (scattering coefficient at $520 \mathrm{~nm}$ ) and the MAAP (absorption coefficient at $670 \mathrm{~nm}$ ). For the nephelometer, only results with sample $\mathrm{RH}<40 \%$ were considered. For the MAAP it was checked that the RH did not exhibit a high gradient during measurement. Unfortunately, also the nephelometer suffered from technical problems during the measurement period. The $1 \mathrm{~h}$ data coverage for the nephelometer was $58 \%$.

The scattering coefficient needs to be corrected due to several artifacts. The transport line losses were first calculated to the nephelometer. The transport losses ranged from $0.6 \%$ for $100 \mathrm{~nm}$ particles to $20 \%$ for $10 \mu \mathrm{m}$ particles. After estimating the transport line losses, a truncation correction was calculated. The truncation correction comes from the fact that the angle of measurement in Ecotech Nephelometer is 10-170 and not a full $180^{\circ}$. The light scattered forward from coarse particles gives the highest contribution to this correction. The 

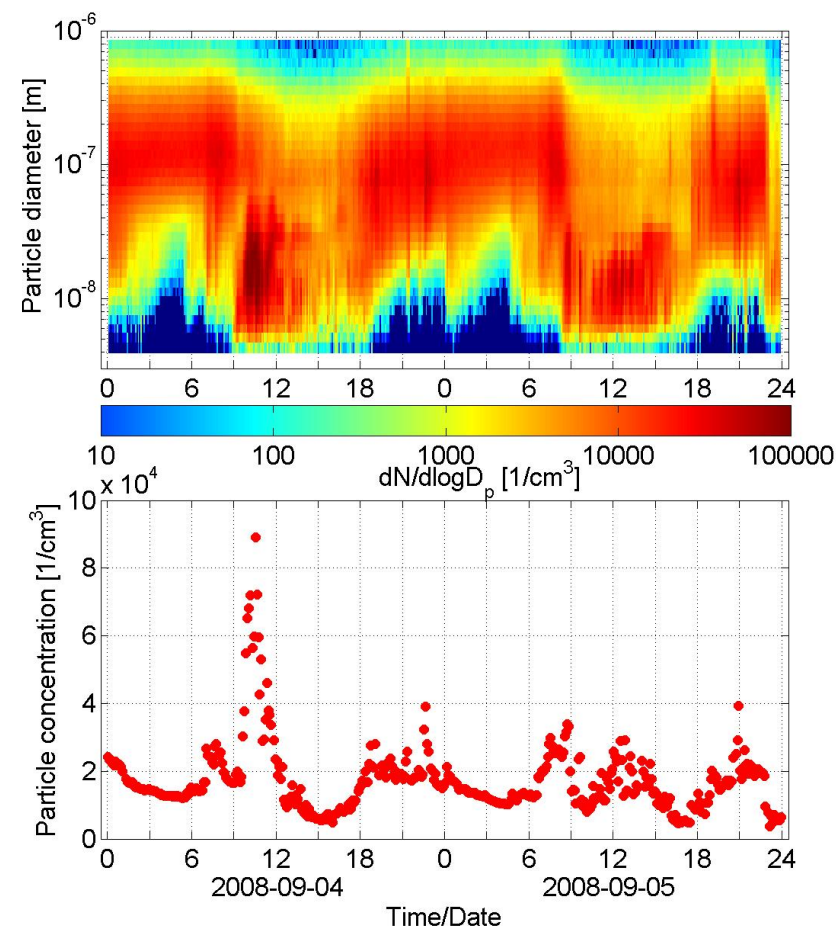

Fig. 5. Nucleation event and subsequent growth as seen during 4-5 September 2008 in Gual Pahari.

first estimate for truncation correction was estimated with the aid of typical particle number size distributions during different seasons obtained from the DMPS and the APS from $4 \mathrm{~nm}$ to $10 \mu \mathrm{m}$ and Mie-scattering calculations. The refractive index used in the calculations was assumed to be mixture of soot (7\%), soluble (74\%) and insoluble $19 \%$ material. This estimate was based on chemical analysis of aerosol filter samples from the Partisol instrument.

From Mie calculation a simple estimation of the truncation error was done. The overlapping of DMPS and APS size distribution data was suite sparse, so only rough estimation is presented here. This first rough estimate gives correction factors varying from about 1.1 to 1.5 with a mean of 1.2. A more precise estimation of the correction factor will be a future task when the optical properties are utilized in more detail. However, this estimation illustrates that the coarse mode gives a significant contribution to the scattering in Gual Pahari and cannot be neglected in the analysis. The other correction arising from the illumination function of the nephelometer has been discussed recently (Müller et al., 2009). However, realizing this correction was not yet feasible in this study, because the nephelometer has not been inter-compared outside the factory.

The average truncation corrected scattering coefficient at $520 \mathrm{~nm}$ was $758 \mathrm{Mm}^{-1}$, while the corresponding absorption coefficient at $670 \mathrm{~nm}$ was $81 \mathrm{Mm}^{-1}$ (Table 2). The highest values were found during the post-monsoon season

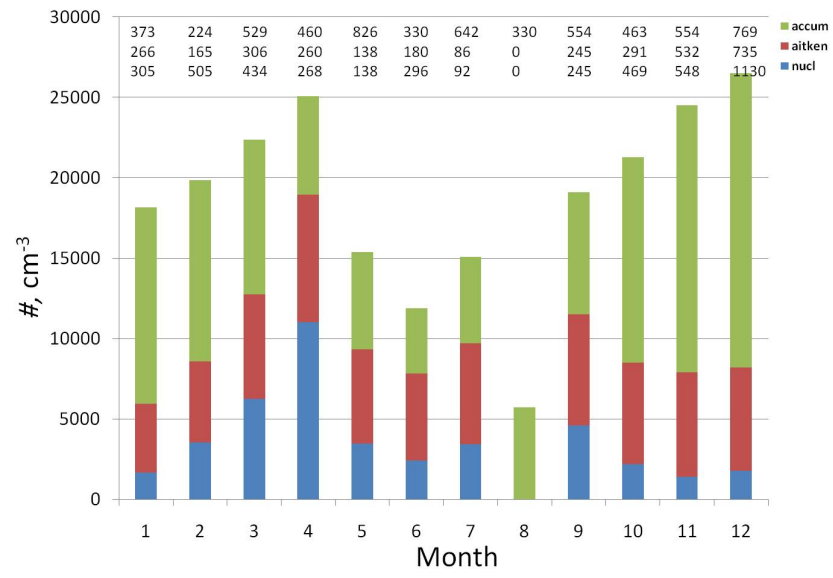

Fig. 6. Annual variation of total and modal particle number concentrations during the measurement period. Nucleation mode $<25 \mathrm{~nm}$, Aitken mode $25 \mathrm{~nm}<d_{p}<75 \mathrm{~nm}$, accumulation mode $>75 \mathrm{~nm}$. Number of hours measured during each month for each mode is also shown.

and the winter; the maximum $1 \mathrm{~h}$ scattering coefficient was $9750 \mathrm{Mm}^{-1}$ and the absorption coefficient was $343 \mathrm{Mm}^{-1}$. The scattering coefficient followed closely the behavior of the $\mathrm{PM}_{10}$ mass and the total volume from the APS. The high seasonal standard deviations especially during the postmonsoon season illustrate the diurnal variability of the data and the presence of pollution episodes.

\subsection{Seasonal variation}

The seasonal variation of the aerosol characteristics was very distinct in Gual Pahari. The highest concentrations were observed during the winter and the lowest during the rainy season. This was an expected result due to the high contrast in the rainy and the dry seasons' meteorology.

After winter, the concentrations began to decrease in the pre-monsoon period as the temperatures increased thus increasing the natural convection and the boundary layer height. It has to be noted that even though the average concentrations decreased, there were some high concentration episodes, especially visible in the $\mathrm{PM}_{10}$ and the APS data (Fig. 4). These were most likely dust events, and according to Moorthy et al. (2007), April and May represent the active time for dust storms in India. The nucleation and Aitken mode dominated the particle number concentration in the pre-monsoon season (Fig. 6). The age of the air masses can be estimated from the ratio of Aitken and accumulation mode particles, $N_{\text {ait }} / N_{\text {acc }}$, see Fig. 7. During the pre-monsoon season, this ratio obtained a wide range of values from 0.3 up to 7 (with an average of about 1). The low values indicate that the air was quite aged, while the high values were often connected with new particle formation. The average monthly fraction of the coarse mode varied between $40 \%$ and $50 \%$ 


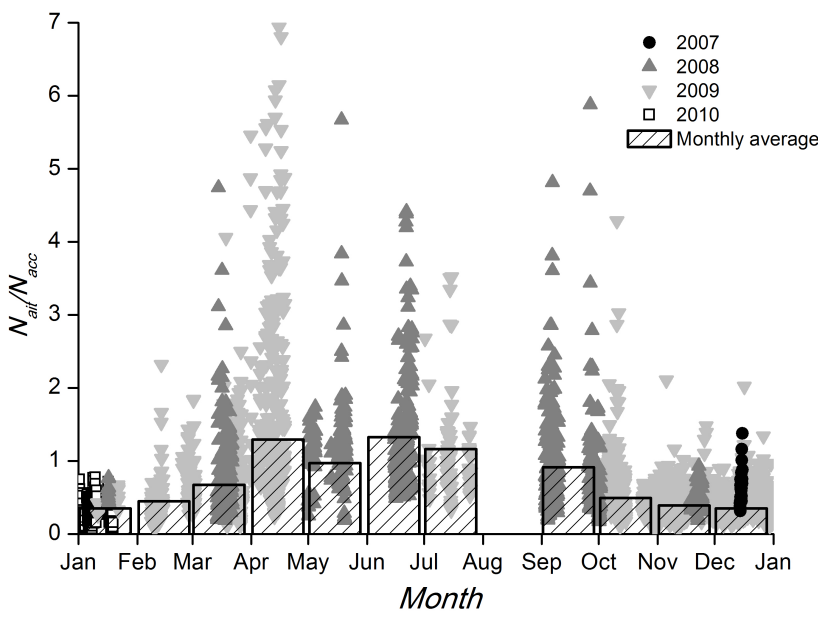

Fig. 7. Ratio of Aitken and accumulation mode particles, $N_{\text {ait }} / N_{\text {acc }}$. Each point is $1 \mathrm{~h}$ average, bars correspond to a monthly average from the full data set.

(Fig. 8a), and the fraction of $\mathrm{BCe}$ from $\mathrm{PM}_{10}$ from $4 \%$ to $7 \%$ (Fig. 8b) with a decreasing trend towards the rainy season.

As the pre-monsoon turned into the rainy season, concentrations decreased further due to wet deposition. During the rainy season, there was a strong contribution of the coarse mode, about $50 \%$. The contribution was even stronger during the 2008 rainy season. This is counter-intuitive, as the coarse mode should have been more efficiently scavenged by the wet deposition processes. We assume that the high fraction of the coarse mode might be related to the characteristic times needed for the different sized particles to contribute to the aerosol mass. The rain during the monsoon in the Gual Pahari area is sporadic by nature. To increase the aerosol mass substantially, the secondary fine particles need a longer time to grow after scavenged by wet deposition, where as the emissions from the primary sources have a potential to increase the mass more rapidly. This was especially visible during 2008 when high concentration episodes in the coarse more were encountered also during the rainy season. Also the $\mathrm{BCe}$ fraction had high values during the rainy season, between $6 \%$ and $8 \%$, which indicates that their sources lied in primary emissions. The ratio $N_{\text {ait }} / N_{\text {acc }}$ received values from 0.5 up to 5 , indicating the presence of new particle formation, preference of the accumulation mode removal by wet deposition, and that the air masses were fresh rather than aged. During the closing stages of the rainy seasons, $N_{\text {ait }} / N_{\text {acc }}$ started to decrease showing that the air masses began to age again.

As the post-monsoon period kicked in, the particle concentrations increased. The arriving air mass occurrence shifted from the ocean areas to the north-west, and the loss mechanism of wet removal disappeared. The high contribution of both nucleation and Aitken mode particles reveals that secondary processes still provided majority of particles numberwise. However, the average values of $N_{\text {ait }} / N_{\text {acc }}$ decreased (Fig. 7), as did the fraction of the coarse mode mass. This in-

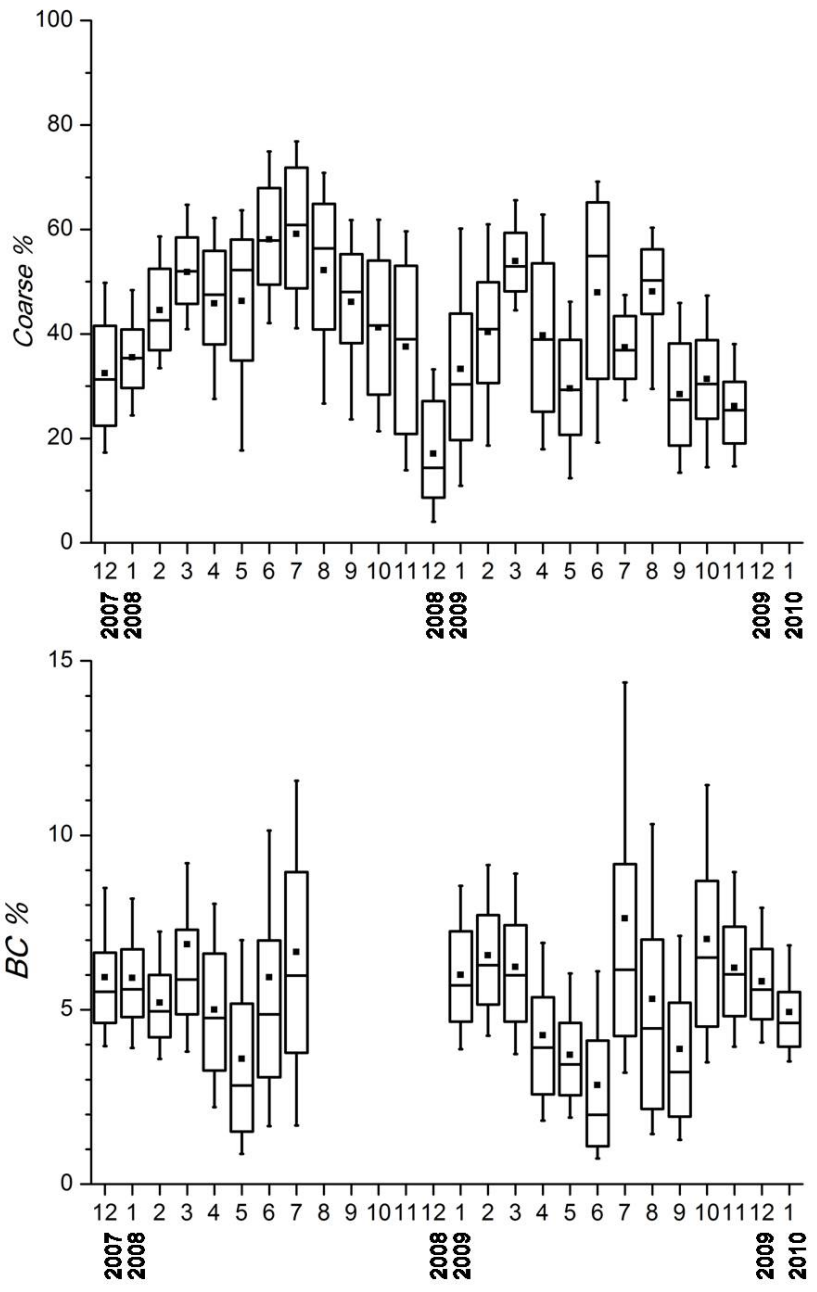

Fig. 8. (upper) Fraction of the coarse mode $\left(\mathrm{PM}_{10}-\mathrm{PM}_{2.5}\right)$ of the $\mathrm{PM}_{10}$ mass. (lower) Fraction of $\mathrm{BCe}$ of the $\mathrm{PM}_{10}$ mass. In figures, $10 \%$ percentile (error bar), $25 \%$ percentile (box bottom), median (horizontal line), mean (rectangle), $75 \%$ percentile (box top), and $90 \%$ percentile (error bar) calculated from hourly averages are presented for each month.

dicates that the air masses aged, and the fine fraction started to dominate the aerosol characteristics.

During winter, the highest mass concentrations were encountered. The winter and post-monsoon periods had nearly the same source areas according to trajectory occurrence, so the only difference should have arisen from the meteorology. The night- and day time temperatures had their lowest values, thus decreasing natural convection and the boundary layer height. This, in addition to weakened removal mechanisms, created a stagnant situation with high aerosol mass concentrations. However, the total number concentration of particles decreased, as the frequency of new particle formation decreased. The contribution of the coarse mode reached its lowest values, and from the few measurements that we were able to make, the ratio of Aitken to accumulation mode 



Fig. 9. Diurnal variation of (A) $\mathrm{PM}_{10}$, (B) Coarse mode, (C) Percentage of $\mathrm{PM}_{2.5}$ of $\mathrm{PM}_{10}$, (D) Percentage of $\mathrm{BCe}_{\text {of }} \mathrm{PM}_{10}$.

particles had its annual lowest values; with an average of about 0.4 . This illustrates an aged aerosol with a dominating accumulation mode. During winter, the BCe $\%$ of the $\mathrm{PM}_{10}$ mass had values around 5.5\%.

\subsection{Diurnal variation}

The diurnal variation of the aerosol properties was much dependent on the prevailing season, even though outside the rainy season the general characteristics were rather similar. Figure 9 illustrates the aerosol mass- related behavior during different seasons.

The height of the planetary boundary layer (PBL) plays an important role in the diurnal variation of the aerosol properties in Gual Pahari. The boundary layer heights were obtained from ECMWF (European Centre for Medium-range Weather Forecasts) model runs for $3 \mathrm{~h}$ intervals, and can be seen in Fig. 10 for the pre-monsoon season. The maximum aerosol concentrations occurred in the morning around 07:00-08:00 a.m., because of the low boundary layer height and the morning traffic and cooking activities in the area. At this time, the $\mathrm{PM}_{2.5}$ fraction of the $\mathrm{PM}_{10}$ mass obtained its highest values. The warm day time temperatures initiated convective mixing, which is visible as a minimum in the diurnal PM mass data. This mixing was strongest with highest temperatures, i.e. during the pre-monsoon season. During this time also the $\mathrm{BCe}$ fraction of $\mathrm{PM}_{10}$ dropped to a minimum from the maximum observed during the morning and evening traffic hours. This is probably because BC is not very dense $\left(\sim 1 \mathrm{~g} \mathrm{~cm}^{-3}\right)$ (Hess et al., 1998), and would thus be ef- fectively lifted from the ground level. The same has been observed by Tripathi et al. (2007) with measurements of BCe vertical distribution in Kanpur, central India. Other maxima in mass concentrations were observed in the evening, due to traffic and reduction of the boundary layer height. This also applies when the sizes of particles are considered. During the strong mixing in the day-time, the fraction of particles below $1 \mu \mathrm{m}$ decreased, as the larger and heavier aerosol were less strongly elevated.

Quite interestingly, the number concentration did not follow the diurnal mass trend. While the same morning maximum could be observed, there was another maximum around 13:00 (Fig. 10). The reason for this was rather strong new particle formation that was observed in Gual Pahari. The decreased condensation sink due to convective mixing during boundary layer evolution was the key factor enabling the new particle formation to kick in (Figs. 5, 9 and 10). A similar conclusion was made by Mönkkönen et al. (2005), who observed nucleation events in New Delhi during OctoberNovember 2002. Apparently the vapor source rate in Gual Pahari was very high, because nucleation events were observed in about $70 \%$ of the available measurement days. Also the intensity of sun radiation may have played a role in the nucleation process. The particles grew rapidly reaching the Aitken and accumulation mode size thus contributing considerably to the aerosol load. In November, less particle formation was observed, as the low night- and day time temperatures led into weaker natural convection and a higher condensation sink. 


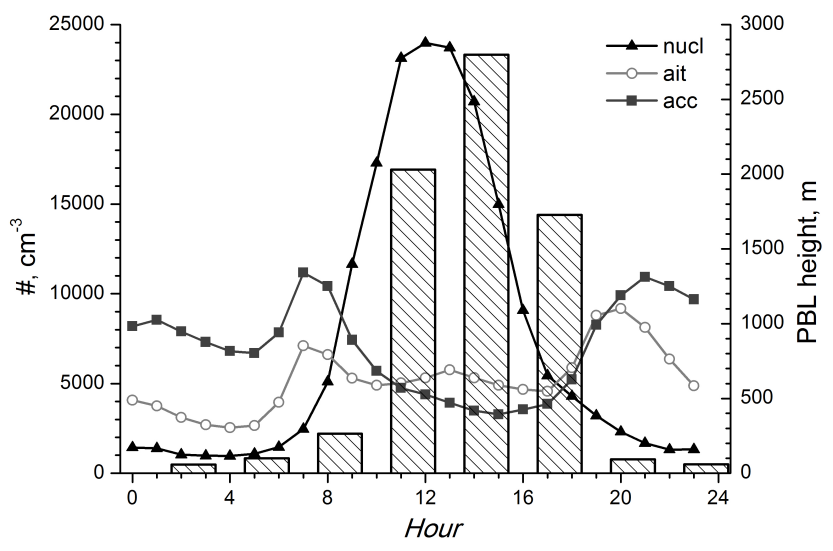

Fig. 10. Modal particle number concentrations from the DMPS during the pre-monsoon period. Also the pre-monsoon boundary layer height (PBL) is shown.

\subsection{Aerosol sources and sinks}

While the sources and sinks were already briefly mentioned in the earlier chapters, this chapter will sum them up. Wind direction did not correlate clearly with any of the aerosol properties, which indicates that there were very few, or none, disturbing local sources. Thus we can assume that the measurements were representative of the regional area.

Trajectory analysis suggested that there were no distinct differences between different source areas outside the rainy season (Fig. 11). The highest concentrations in Gual Pahari occurred when the air masses arrived from the 330$90^{\circ}$, with the corresponding average $\mathrm{PM}_{2.5}$ mass being from

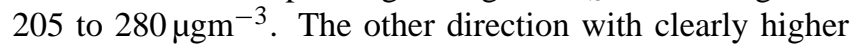
concentrations was the $150-180^{\circ}$ sector (average $\mathrm{PM}_{2.5}$ $\sim 230{\mu \mathrm{gm}^{-3}}$ ). The lowest concentrations occurred when trajectories arrived from the $90-150$ and $210-270^{\circ}$ sector, with an average $\mathrm{PM}_{2.5}$ mass of about $115 \mu \mathrm{gm}^{-3}$. The coarse mode showed very similar behavior to the $\mathrm{PM}_{2.5}$, showing maxima at sectors 60-90 and 150-180 at a concentration of $150 \mathrm{\mu gm}^{-3}$

A high percentage of the aerosol mass consisted of BCe which indicates anthropogenic influence. The percentage of $\mathrm{BCe}$ was higher during the winter; and according to the diurnal pattern of the $\mathrm{BCe}$ fraction, peaks occurred during active traffic hours, i.e. in the morning and in the evening. BCe concentrations behaved similarly in regard to trajectory directions as the PM concentrations. The anthropogenic sources in the area include traffic, city emissions and power production (Reddy and Venkataraman 2002a, b). The strongest anthropogenic contribution occurred 7 and 8 November 2009 when air masses passed close to Delhi and arrived in Gual Pahari in the noon. This created episodically high scattering $\left(>8700 \mathrm{Mm}^{-1}\right)$ and PM-levels $\left(>1900 \mu \mathrm{gm}^{-3} \mathrm{PM}_{10}\right.$; $>1500 \mu \mathrm{gm}^{-3} \mathrm{PM}_{2.5}$ ), see Fig. 4. According to APS data, most of the particle volume resided in a mode at $800 \mathrm{~nm}$.

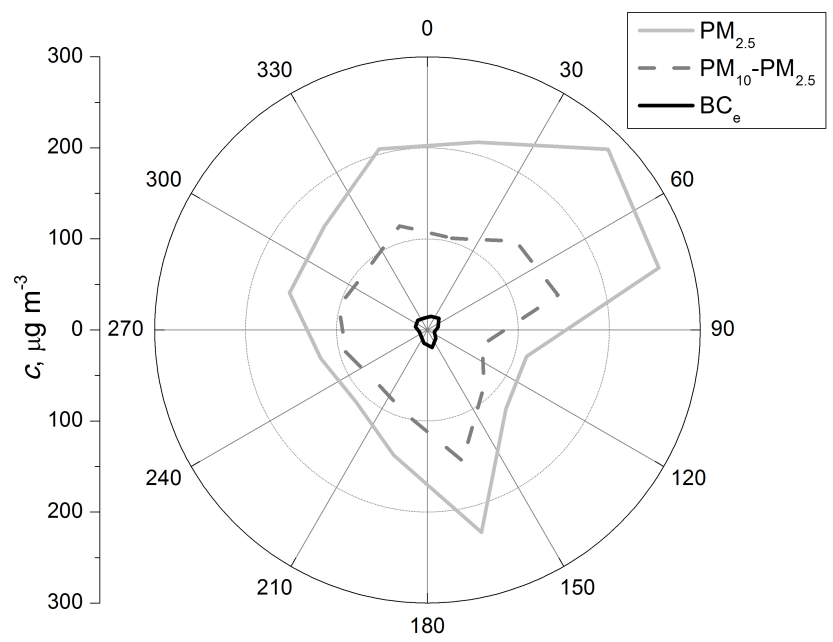

Fig. 11. Average $\mathrm{PM}_{2.5^{-}}$, coarse mode-, and $\mathrm{BCe}$ masses according to the main trajectory sector. Data from the rainy season is not included.

BCe showed elevated values up to $45 \mu \mathrm{g} \mathrm{m}^{-3}$ and total particle count from the DMPS was up to $63000 \mathrm{~cm}^{-3}$. This was a very heavy smog condition which occurred due to light wind $(<0.3 \mathrm{~m} / \mathrm{s})$ and a weak ventilation of the polluted surface air. In addition to anthropogenic plumes, especially the pre-monsoon season exhibited several episodes in the coarse mode that were seen as elevated $\mathrm{PM}_{10}\left(>1000 \mu \mathrm{gm}^{-3} \mathrm{PM}_{10}\right)$ and volume of coarse mode particles. These events did not show equally elevated $\mathrm{PM}_{2.5}$ concentrations and were most likely dust episodes.

Another important source of aerosol particles in the area was new particle formation. As even the smallest particles were present $(>4 \mathrm{~nm})$ in the data, it's apparent that the particle formation took place on-site. At this time it is unknown what the condensable species were and whether they were natural or anthropogenic in nature. However, the nucleated particles grew rapidly reaching the accumulation mode size, thus contributing considerably to the aerosol load.

The major aerosol sink was the rainy season which created efficient wet deposition in the area. This decreased the fraction of particle mass in the $\mathrm{PM}_{2.5}$ size range, i.e. of secondary origin. Thus also the scattering and absorbing coefficients were decreased. However, the average coarse mode concentrations were not so much affected. This might be, as the rains were sporadic in nature, and outside the rain showers the coarse mode (seen from the APS and PM data) had a potential to build up again more rapidly than the secondary aerosol mass in the fine mode. The other major mechanism decreasing the ground level concentrations was based on convective mixing and boundary layer evolution. This diluted the aerosol when sun radiation and the temperature were high, especially during pre-monsoon day time. The lighter and smaller particles were more effectively diluted. 


\section{Conclusions}

We presented the in-situ aerosol measurements conducted during the EUCAARI measurement project in Gual Pahari, India. The seasonal variation of the aerosol characteristics was very distinct in Gual Pahari. The highest concentrations were observed during the winter and the lowest during the rainy season. This was an expected result due to the high contrast in the rainy and the dry seasons' meteorology.

The weakened removal mechanisms during winter created a stagnant, high concentration aerosol pollution situation, which can be deemed to relate to the "Brown Cloud" due to its absorbing nature. In addition to the elevated BCe concentrations, also the fine fraction dominated during the occurrence of the high pollution, illustrating an aged aerosol. The selective dilution of $\mathrm{BC}$ particles over other $\mathrm{PM}_{2.5}$ particles during convection situations suggests that the aerosol at Gual Pahari was, at least partly, externally mixed. During winter, 24-h the average $\mathrm{PM}_{2.5}$ concentration (typical average used for health regulation purposes) was $190{\mu g m^{-3}}^{-3}$ and $\mathrm{PM}_{10}$ concentration was $320 \mathrm{\mu gm}^{-3}$. These levels exceed the national ambient air quality PM standards (Central Pollution Control Board, 2009) in India, which are $60 \mu \mathrm{gm}^{-3}$ for $\mathrm{PM}_{2.5}$ and $100 \mu \mathrm{gm}^{-3}$ for $\mathrm{PM}_{10}$. In fact, only 139 days from the available 569 days (24\%), and 128 from 666 days (19\%) of data were under the standard values for $\mathrm{PM}_{2.5}$ and $\mathrm{PM}_{10}$, respectively. During the rainy season, there was a strong contribution of the coarse mode, about 50\%. This is counterintuitive, as the coarse mode should be more efficiently scavenged by the wet deposition processes. This might be partly because the primary sources could potentially increase the coarse mode quickly between the rain showers. For the fine fraction, the build up process probably needed more time as the secondary particles had to grow to a have a noteworthy mass.

Acknowledgements. This work is funded by the The European Integrated project on Aerosol Cloud Climate and Air Quality Interactions, EUCAARI. Timo Anttila and Ari Halm are acknowledged for technical assistance and staff at TERI's Gual Pahari Retreat for valuable routine maintenance of instruments.

Edited by: A. Wiedensohler

\section{References}

Althausen, D., Engelmann, R., Baars, H., Heese, B., Ansmann, A., Müller D., and Komppula, M.: Portable Raman lidar PollyXT for automated profiling of aerosol backscatter, extinction, and depolarization, J. Atmos. Ocean. Tech., 26, 2366-2378, doi:10.1175/2009JTECHA1304.1, 2009.

Andreae, M. O. and Gelencsér, A.: Black carbon or brown carbon? The nature of light-absorbing carbonaceous aerosols, Atmos. Chem. Phys., 6, 3131-3148, doi:10.5194/acp-6-3131-2006, 2006.
Bollasina, V., Nigam, S., and Lau, K.-M.: Absorbing aerosols and summer monsoon evolution over South Asia: an observational portrayal, J. Climate, 21, 3221-3239, 2008.

Ganguly, D., Jayaraman, A., Rajesh, T. A., and Gadhavi, H.: Wintertime aerosol properties during foggy and nonfoggy days over urban center Delhi and their implications for shortwave radiative forcing, J. Geophys. Res., 111, D15217, doi:10.1029/2005JD007029, 2006.

Hegde, P., Pant, P., Naja, M., Dumka, U. C., and Sagar, R.: South Asian dust episode in June 2006: Aerosol observations in the central Himalayas, Geophys. Res. Lett., 34, L23802, doi:10.1029/2007GL030692, 2007.

Hess, M., Koepke, P., and Schultz, I.: Optical properties ofaerosols and clouds: the software package OPAC, B. Am. Meteorol. Soc., 79, 831-844, 1998.

Hyvärinen, A.-P., Lihavainen, H., Komppula, M., Sharma, V. P., Kerminen, V.-M., Panwar, T. S., and Viisanen, Y.: Continuous measurements of optical properties of atmospheric aerosols in Mukteshwar, Northern India, J. Geophys. Res., 114, D08207, doi:10.1029/2008JD011489, 2009.

Komppula, M., Lihavainen, H., Hyvärinen, A.-P., Kerminen, V.-M., Panwar, T. S., Sharma, V. P., and Viisanen, Y.: Physical properties of aerosol particles at a Himalayan background site in India, J. Geophys. Res., 114, D12202, doi:10.1029/2008JD011007, 2009.

Lau, K.-M. and Kim, K.-M.: Observational relationship between aerosol and Asian rainfall and circulation, Geophys. Res. Lett., 33, L21810, doi:10.1029/2006GL027546, 2006.

Lelieveld, J., Crutzen, P. J., Ramanathan, V., Andreae, M. O., Brenninkmeijer, C. A. M., Campos, T., Cass, G. R., Dickerson, R. R., Fischer, H., de Gouw, J. A., Hansel, A., Jefferson, A., Kley, D., de Laat, A. T. J., Lal, S., Lawrence, M. G., Lobert, J. M., MayolBracero, O. L., Mitra, A. P., Novakov, T., Oltmans, S. J., Prather, K. A., Reiner, T., Rodhe, H., Scheeren, H. A., Sikka D., and Williams, J.: The Indian Ocean Experiment: Widespread air pollution from South and Southeast Asia, Science 291, 1031-1036, 2001.

Meehl, G. A., Arblaster, J. M., and Collins, W. D.: Effects of black car bon aerosols on the Indian monsoon, J. Climate, 21, 28692882, 2008.

Moorthy, K. K., Babu, S. S., Satheesh, S. K., Srinivasan, J., and Dutt, C. B. S.: Dust absorption over the "Great Indian Desert" inferred using ground-based and satellite remote sensing, J. Geophys. Res., 112, D09206, doi:10.1029/2006JD007690, 2007.

Müller, T., Nowak, A., Wiedensohler, A., Sheridan, P., Laborde, M., Covert, D. S., Marinoni, A., Imre, K., Henzing, B., Roger, J.-C., dos Santos, S. M., Wilhelm, R., Wang, Y.-Q., and de Leeuw, G.: Angular illumination and truncation of three different integrating nephelometers: implications for empirical size-based corrections, Aerosol Sci. Tech., 43, 581-586, 2009.

Nakajima, T., Yoon, S.-C., Ramanathan, V., Shi, G.-Y., Takemura, T., Higurashi, A., Takamura, T., Aoki, K., Sohn, B.-J., Kim, S.-W., Tsuruta, H., Sugimoto, N., Shimizu, A. Tanimoto, H., Sawa, Y., Lin, N.-H., Lee, C.-T., Goto, D., and Schutgens, N.: Overview of the atmospheric Brown Cloud East Asian Regional Experiment 2005 and a study of the aerosol direct radiative forcing in east Asia, J. Geophys. Res., 112, D24S91, doi:10.1029/2007JD009009, 2007.

Pathirana, A., Herath, S., Yamada, T., and Swain, D.: Impacts of 
absorbing aerosols on South Asian rainfall. A modelling study, Climatic Change, 85, 103-118, 2007.

Ramanathan, V., Li, F., Ramana, M. V., Praveen, P. S., Kim, D., Corrigan, C. E., Nguyen, H., Stone, E. A., Schauer, J. J., Carmichael, G. R., Adhikary, B., and Yoon, S. C.: Atmospheric brown clouds: Hemispherical and regional variations in longrange transport, absorption, and radiative forcing, J. Geophys. Res., 112, D22S21, doi:10.1029/2006JD008124, 2007a.

Ramanathan, V., Ramana, M. V., Roberts, G., Kim, D., Corrigan, C., Chung, C., and Winker, D.: Warming trends in Asia amplified by brown cloud solar absorption, Nature, 448, doi:10.1038/nature06019, 2007b.

Reddy, M. S. and Venkataraman, C.: Inventory of aerosol and sulphur dioxide emissions from India: I - Fossil fuel combustion, Atmos. Environ., 36, 677-697, 2002.

Reddy, M. S. and Venkataraman, C.: Inventory of aerosol and sulphur dioxide emissions from India. Part II - biomass combustion, Atmos. Environ., 36, 699-712, 2002.
Satheesh, S. K. and Ramanathan, V.: Large differences in tropical aerosol forcing at the top of the atmosphere and Earth's surface, Nature, 405, 60-63, 2000.

Singh, R. P., Sagnik, D., Tripathi, S. N., and Tare, V.: Variability of aerosol parameters over Kanpur, northern India, J. Geophys. Res., 109, D23206, doi:10.1029/2004JD004966, 2004.

Sirohi, S. and Michaclowa, A.: Sufferer and cause: Indian livestock and climate change, Climatic Change, 85, 285-298, 2007.

Stohl, A., Wotawa, G., Seibert, P., and Kromp-Kolb, H.: Interpolation errors in wind fields as a function of spatial and temporal resolution and their impact on different types of kinematic trajectories, J. Appl. Meteorol., 34, 2149-2165, 1995.

Tripathi, S. N., Srivastava, A. K., Dey, S., Satheesh, S. K., and Krisnamoorthy, K.: The vertical profile of atmospheric heating rate of black carbon aerosols at Kanpur in northern India, Atmos. Environ., 41, 6909-6915, 2007.

Weingartner, E., Saathoff, H., Schnaiter, M., Streit, N., Bitnar, B., and Baltensperger, U.: Absorption of light by soot particles: determination of the absorption coefficient by means of aethalometers, J. Aerosol Sci., 34, 1445-1463, 2003. 